\title{
Evaluating the TRMM Multisatellite Precipitation Analysis for Extreme Precipitation and Streamflow in Ganjiang River Basin, China
}

\author{
Shanshan Jiang, ${ }^{1}$ Zengxin Zhang, ${ }^{1,2}$ Yuhan Huang, ${ }^{1}$ Xi Chen, ${ }^{3}$ and Sheng Chen ${ }^{4,5}$ \\ ${ }^{1}$ Joint Innovation Center for Modern Forestry Studies, College of Biology and the Environment, Nanjing Forestry University, \\ Nanjing 210037, China \\ ${ }^{2}$ State Key Laboratory of Satellite Ocean Environment Dynamics, Second Institute of State Oceanic Administration, \\ Hangzhou 310012, China \\ ${ }^{3}$ State Key Laboratory of Hydrology-Water Resources and Hydraulics Engineering, Hohai University, Nanjing 210098, China \\ ${ }^{4}$ School of Atmospheric Sciences, Sun Yat-sen University, Guangzhou 510275, China \\ ${ }^{5}$ Guangdong Province Key Laboratory for Climate Change and Natural Disaster Studies, Guangzhou 510275, China
}

Correspondence should be addressed to Zengxin Zhang; nfuzhang@163.com

Received 20 January 2017; Revised 12 April 2017; Accepted 23 April 2017; Published 29 June 2017

Academic Editor: Zheng Duan

Copyright (C) 2017 Shanshan Jiang et al. This is an open access article distributed under the Creative Commons Attribution License, which permits unrestricted use, distribution, and reproduction in any medium, provided the original work is properly cited.

\begin{abstract}
Based on the observed precipitation data and TRMM (Tropical Rainfall Measuring Mission) 3B42 RTV7 and 3B42 V7 precipitation products from 2003 to 2010, the extreme precipitation and streamflow in the Ganjiang River basin were analyzed. The VIC hydrological model was used to simulate the streamflow driven by RTV7/V7 precipitation products in the Ganjiang River basin. The results show that (1) both of the RTV7 and V7 precipitation products have good applicability in precipitation estimation in the Ganjiang River basin and the correlation between the observed precipitation and RTV7 (V7) was as higher as 0.85 (0.86); (2) the RTV7/V7 precipitation products can well be used to simulate the streamflow by using the VIC hydrological model and the correlation between the observed streamflow and simulated streamflow driven by RTV7 (V7) products was as high as 0.86 (0.89); (3) the extreme precipitation varied greatly in the Ganjiang River basin and both of the RTV7 and V7 can capture the pattern of extreme precipitation in the Ganjiang River basin; however, higher extreme precipitation can be found in the northern Ganjiang River basin; (4) the extreme streamflow simulated driven by RTV7/V7 products agreed well with the observed extreme streamflow in the Ganjiang River basin. This study indicated that the TRMM 3B42 RTV7 and V7 products can be well used in the estimation of extreme precipitation and extreme streamflow.
\end{abstract}

\section{Introduction}

Extremely climate events may exert serious impacts on human society and have drawn increasing concerns in the world $[1,2]$. The spatial and temporal variability of precipitation are of paramount importance in understanding hydrological processes and land-atmosphere interactions [3, 4]. However, the accurately precipitation estimation in a large scale is difficult [5]. The direct observation of ground meteorological station is more accurate but affected by station network density, terrain, and other factors [6], while the ground-based radar observation is affected by the electronic signals, operating environment, and other sources of error which has a greater uncertainty in the complex terrain (Yang et al., 2006). To address this problem, a number of remotely sensed precipitation products with high spatial and temporal resolution have been developed [7]. Recently, the emergence of meteorological satellites greatly met the demand for precipitation data which is one of the important measures to monitor the global and regional precipitation [8].

Among of them, TRMM (Tropical Rainfall Measuring Mission) precipitation products have been widely used in various climatic and hydrological studies $[9,10]$. The TRMM precipitation products are a joint mission between NASA and 
the Japan Aerospace Exploration Agency (JAXA) designed to monitor and study tropical rainfall. The TRMM satellite was launched in November 1997 with a designed orbit height of $350 \mathrm{~km}$ and inclination of 35 degrees [8]. It provides precipitation products with high temporal $(3 \mathrm{~h})$ and spatial $(25 \mathrm{~km} \times 25 \mathrm{~km})$ resolution, covering the globe between the latitude bands of $50^{\circ} \mathrm{N} \sim 50^{\circ} \mathrm{S}$ [7]. The TRMM multisatellite precipitation analysis (TMPA) consists of two products: nearreal-time (3B42RT) and research-grade (3B42). The former provides quick, less accurate estimates suitable for monitoring activities; the latter provides more accurate estimates more suitable for research [5]. These products have been widely used for various climatic and hydrologic studies [4, 1113]. For example, Chen et al. [14] found that 3B42 V7 clearly improves upon 3B42 V6 over China in terms of daily mean precipitation; Yong et al. (2014b) found that assessments indicate that RTV7 represents a substantial improvement over RTV6 with respect to the systematic bias in the lowlatitude Mishui basin; Liu [5] found that more rain events are found in 3B42 V7 than those in 3B42 V6 in both JJA and DJF. Yang and Geng [15] evaluated the 3B42V7 and 3B42RTV7 from 2001 to 2011 in the Huaihe River basin and pointed out that both of the RTV7 and V7 precipitation products presented overvalued phenomenon, but the V7 performed better than RTV7.

Although growing, the application of satellite data for hydrological applications is still very limited [16]. The hydrologic evaluation of 3B42 products has also been conducted, such that Tobin and Bennett (2009) utilize and compare the performance of rain gauge and TRMM $3 \mathrm{~B} 42 \mathrm{~V} 6$ data by using the SWAT hydrological modeling in South Texas and northern Mexico; Jiang et al. (2012) employed the semidistributed Xinanjiang model to evaluate three widely used satellite precipitation products (TMPA 3B42V6, TMPA 3B42RT, and CMORPH) in South China and found that these satellite precipitation products have better performance in the streamflow simulation; Xue et al. [17] explored the improvements of the 3B42V7 algorithm relative to its predecessor 3B42V6 using the Coupled Routing and Excess Storage (CREST) hydrologic model in the mountainous Wangchu basin of Bhutan and found that the 3B42V7 has obvious advantages compared to that of 3B42V6 in the hydrological utility. Jiang et al. [18] evaluated the ability of TRMM 3B42V7 product in hydrological simulation and forecasting over the Mishui River basin with Xin'anjiang hydrological model and found that the TRMM 3B42V7 product has a better ability in capturing the changes of daily precipitation and streamflow.

Accurate streamflow simulation is very important in the prediction of floods and water resource management. With the development of computer technology, distributed hydrological models play an important role in the hydrological research [7]. In this study, the VIC (Variable Infiltration Capacity) hydrological model was combined with TRMM precipitation data to simulate the streamflow in the Ganjiang River basin. The VIC model was originally developed jointly at the University of Washington and Princeton University [19]. It is a macroscale hydrology model used to simulate various hydrologic variables as well as kinetic energy variables. The VIC hydrological model has been widely used in the world. For example, Su et al. [19] evaluated TRMM 3B42-V6 data by using the VIC hydrology model in the La Plata Basin and they found that the VIC model with TRMM data overestimated peak flows while representing low flows satisfactorily. In addition, TRMM is used in numerical prediction models of climate and surface energy balance; Pan et al. [20] took the TRMM's precipitation products as input to the VIC model and found that the simulated surface flux had been improved [8].

Although the TRMM data have been applied in the precipitation and streamflow variabilities in the Ganjiang River basin, for example, Tang et al. [21] found that the 3B42RTV7 and $3 \mathrm{~B} 42 \mathrm{~V} 7$ precipitation products were very close to that of the observed precipitation in the Ganjiang River basin. Chen et al. [22] found that 3B42V6 and 3B42V7 show better agreement with gauge observation than 3B42RTV6 and 3B42RTV7 over the Ganjiang River basin. Huang et al. $[9,10]$ found that $3 \mathrm{~B} 42 \mathrm{~V} 6,3 \mathrm{~B} 42 \mathrm{~V} 7$, and 3B42RTV7 had a good ability to estimate streamflow in the Ganjiang River basin by using VIC hydrological model.

Although the evaluation of TRMM multisatellite precipitation data has been investigated in many areas over ten years, there is few research focused on extreme precipitation and extreme streamflow based on TRMM precipitation in a river basin $[23,24]$. Therefore, in this paper, we will analyze the spatial and temporal characteristics of extreme precipitation and streamflow by using the TRMM data and VIC hydrological model in the Ganjiang River basin. This work might be benefit to the improvement for the monitoring, modeling, and forecasting techniques in extreme precipitation and streamflow by using satellite precipitation products.

\section{Date and Method}

2.1. Study Area. Ganjiang River basin is the primary tributary of the Poyang Lake River basin (see Figure 1). The drainage area is about $83,500 \mathrm{~km}^{2}$, accounting for $51 \%$ of the Poyang Lake River basin [25]. The topography in this basin is complex and the elevation ranges from 2 to $2120 \mathrm{~m}$ above sea level. Low hills lie in the central part of the basin while alluvial plains govern the lower reaches. The Ganjiang River basin belongs to subtropical humid monsoon climate and receives approximately $1400-1800 \mathrm{~mm}$ of precipitation per year [19]. The heaviest rainfall occurs in the plum rain season between April and June, while monsoon and typhoon rainstorms frequently occur between July and September $[9,10]$.

2.2. Data. The surface observation data are provided by the Meteorological Bureau China climate data center and the daily rainfall data from 35 meteorological stations in the Ganjiang River basin from 2003 to 2010 (Figure 1). The 3B42 TMPA datasets (3B42 RTV7 and 3B42 V7) used in this study were downloaded from the NASA website (http://trmm.gsfc .nasa.gov/). It has a high temporal $(3 \mathrm{~h})$ and spatial $\left(0.25^{\circ} \times\right.$ $0.25^{\circ}$ ) resolution $[1,14,25]$. And Waizhou hydrological station was chosen as the outlet of Ganjiang River basin.

2.3. Statistical Indices. Correlation coefficient (CC), root mean square error (RMSE), and relative bias (Bias) were 


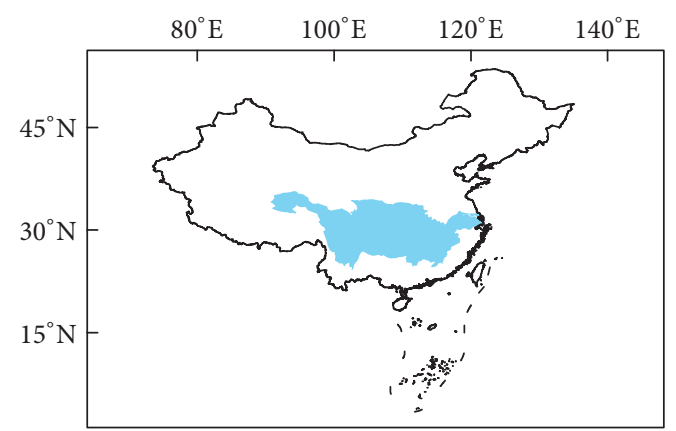

(a) China

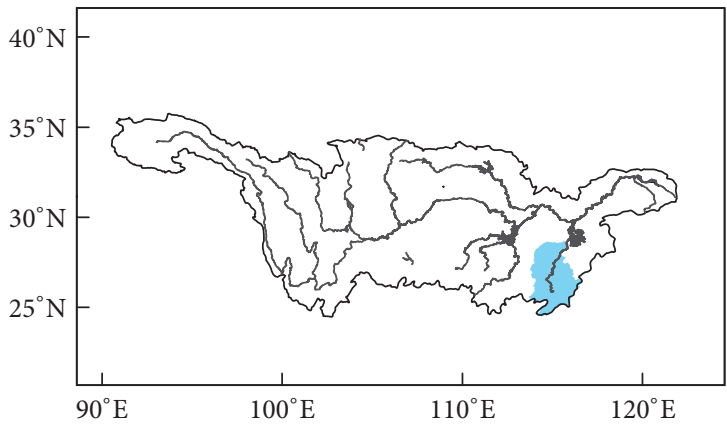

(b) The Yangtze River basin

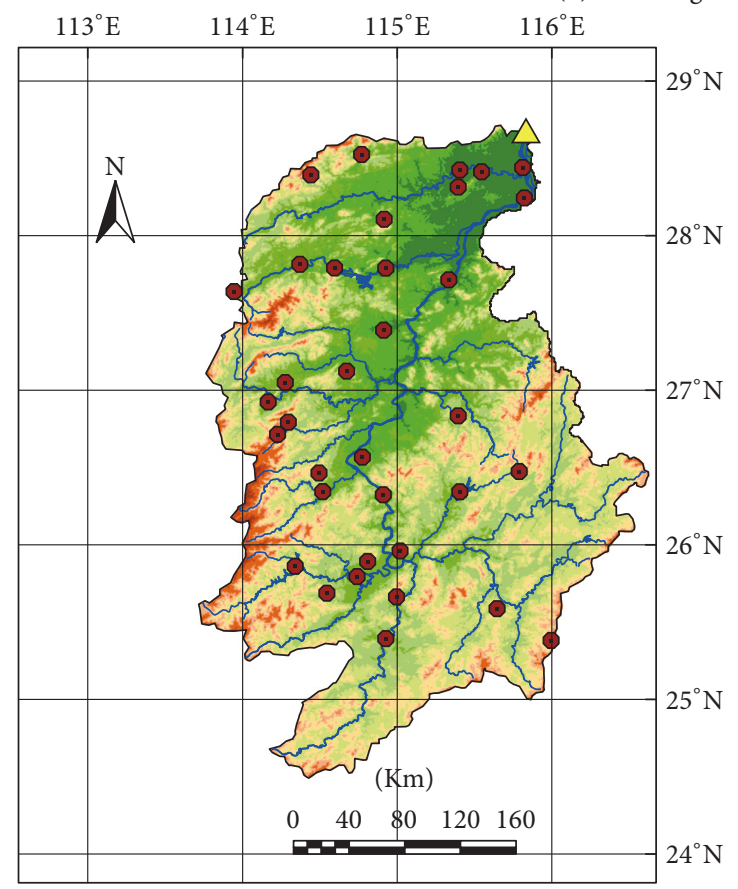

$$
\begin{aligned}
& \triangle \text { Streamflow station } \\
& \text { - Rainfall gauge } \\
& \text { - River } \\
& \text { Dem (m) } \\
& \text { - 1-50 } \square \text { 401-600 } \\
& \square \text { 51-100 } \square \text { 601-800 } \\
& \square \text { 101-150—801-1200 } \\
& \square \text { 151-250 } \square 1201-1600 \\
& \square \text { 251-400 1601-2100 }
\end{aligned}
$$

(c) The Ganjiang River basin

FIGURE 1: Location of Ganjiang River basin and gauge station.

used to measure the differences between the gauged and satellite estimated precipitation [26]. The CC, RMSE, and RB are also can be used to assess the performance of simulated streamflow. Besides, the Nash-Sutcliffe (NSCE) index is used to quantify how well the two hydrological models are. They are defined by the following equations:

$$
\mathrm{CC}=\frac{\sum_{i=1}^{n}(\mathrm{OBS} i-\overline{\mathrm{OBS}}) \sum_{i=1}^{n}(S I M i-\overline{S I M})}{\sqrt{\sum_{i=1}^{n}(\mathrm{OBSi}-\overline{\mathrm{OBS}})^{2} \sum_{i=1}^{n}(S I M i-\overline{S I M})^{2}}},
$$

$$
\begin{aligned}
\text { RMSE } & =\sqrt{\frac{\sum_{i=1}^{n}(O B S i-S I M i)^{2}}{n}}, \\
\text { Bias } & =\left[\frac{\sum_{i=1}^{n} S I M i-\sum_{i=1}^{n} O B S i}{\sum_{i=1}^{n} O B S i}\right] \times 100, \\
\text { NSCE } & =1-\frac{\sum_{i=1}^{n}(O B S i-S I M i)^{2}}{\sum_{i=1}^{n}(O B S i-\overline{O B S})^{2}} .
\end{aligned}
$$




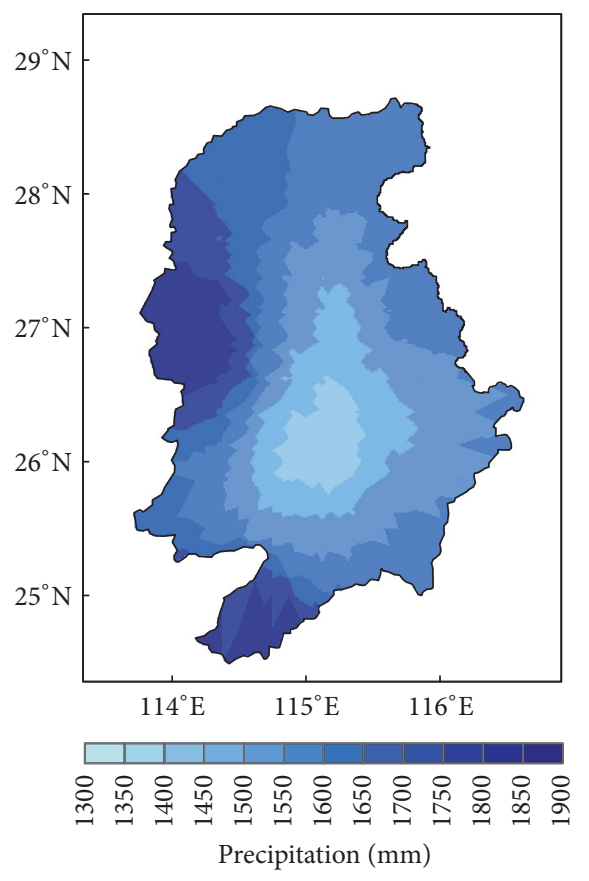

(a) Obs

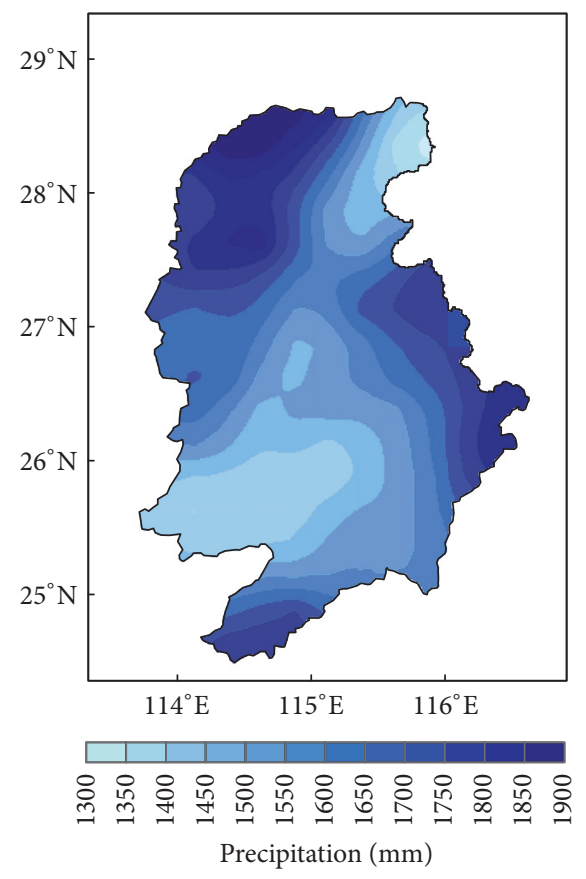

(b) RTV7

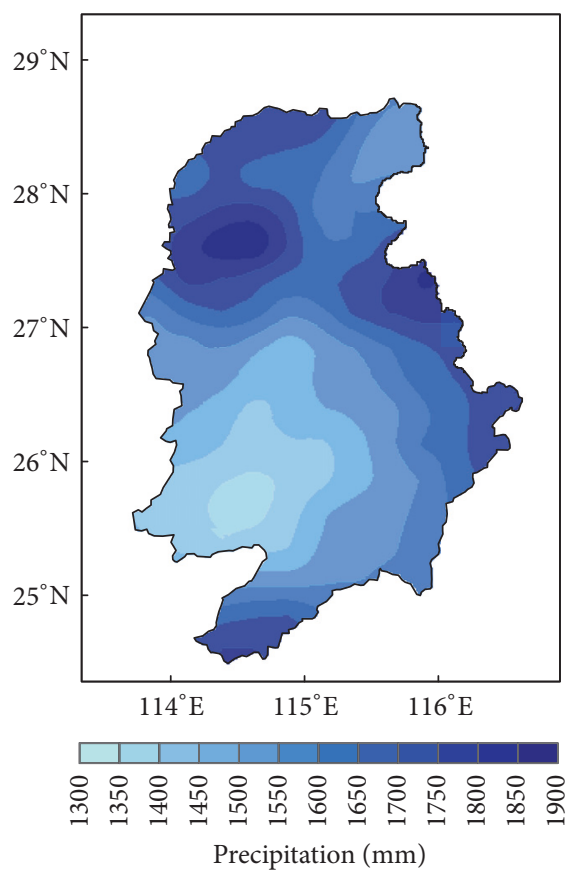

(c) V7

FIGURE 2: Spatial distribution of annual mean precipitation in the Ganjiang River basin from TMPA and observed data from 2003 to 2010.

\section{Result}

3.1. Evaluation of TRMM Precipitation Products in the Ganjiang River Basin. Figure 2 showed the spatial distribution of annual mean precipitation over Ganjiang River basin derived from gauge observation and two TMPA products from 2003 to 2010. The annual mean precipitation in the Ganjiang River basin was $1583.8 \mathrm{~mm}$, and the precipitation estimated by RTV7 and V7 was $1594.1 \mathrm{~mm}$ and $1572.4 \mathrm{~mm}$, respectively. Annual mean precipitation decreases from the south and west $(>1700 \mathrm{~mm} / \mathrm{a})$ to the east and central of the Ganjiang basin $(<1400 \mathrm{~mm} / \mathrm{a})$ (Figure $2(\mathrm{a})$ ). It can be seen that all the TMPA products have similar pattern to that of observed precipitation in the Ganjiang River basin. Tang et al. [21] also found similar results who evaluated the accuracy of TRMM precipitation products (3B42V7 and 3B42RTV7) 


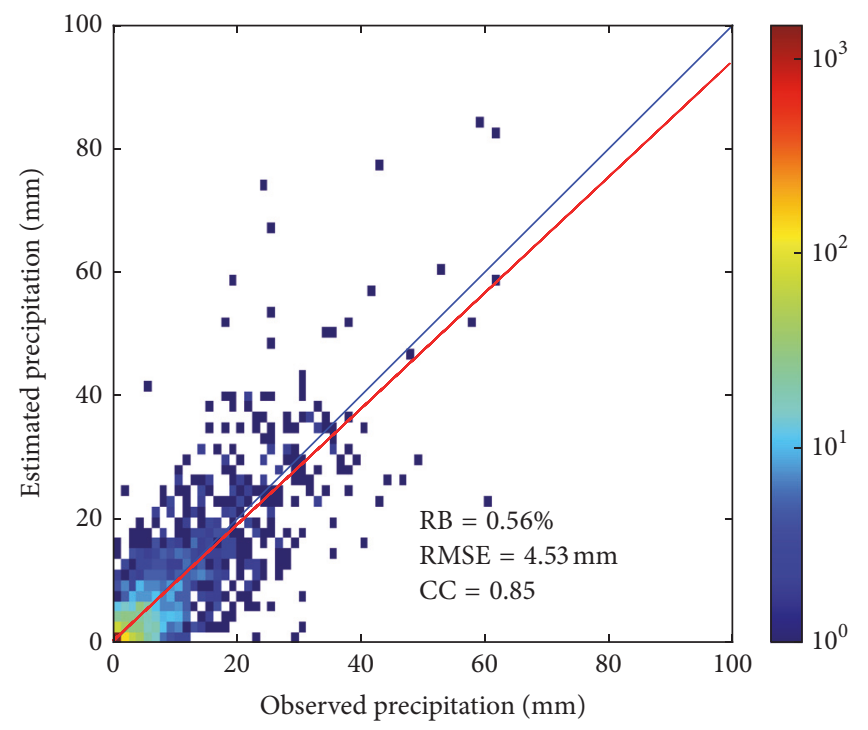

(a) RTV7

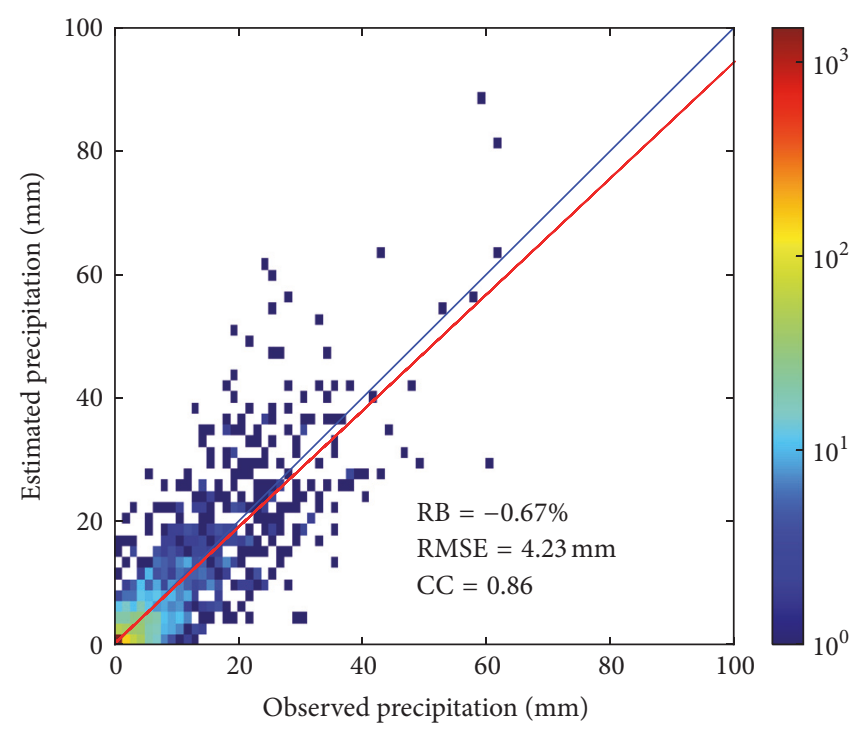

(b) V7

FIGURE 3: Scatter plots of TMPA versus observed precipitation in the Ganjiang River basin ((a) RTV7; (b) V7).

with 310 rainfall sites in the Ganjiang River basin from 2003 to 2009 and they thought that the TRMM satellite data in the Ganjiang River basin had the potential to replace the ground site observation. However, it was clear that the V7 product had been significantly improved compared to that of RTV7 for the whole basin, although both of the RTV7 and V7 overvalued the annual mean precipitation in most area of the Ganjiang River basin. The RTV7 overestimated annual mean precipitation in the north and east of Ganjiang River basin while being underestimated in the west of Ganjiang River basin (Figure 2(b)).

There was a distinct improvement for the 3B42 V7 compared to that of 3B42 RTV7 in the north and east of the Ganjiang River basin where the TRMM overestimated the precipitation (Figure 2). Lower precipitation can be found in the middle reaches of the Ganjiang River, and there was an obvious "basin" pattern in the observation data. However, this phenomenon did not appear in the TRMM satellite precipitation. This is because the precipitation in the Ganjiang River basin is affected obviously by the complex terrain. More precipitation can be found in the mountain areas in the Ganjiang River basin, and the precipitation estimation for the satellite precipitation products was also affected by complex terrain. Zhu et al. [27] also found that the error between the TRMM data and the measured data decreases as the elevation increases in Hengduan Mountains region. Moreover, both of RTV7 and V7 products overestimated the precipitation, so the lower precipitation center was not shown in the TMPA data (Figures 2(b) and 2(c)).

To better evaluate the TMPA precipitation in the Ganjiang River basin, the plots of RTV7 (V7) versus gauge observed precipitation were shown in Figure 3. There were totally 35 selected grid boxes that contain at least one gauge. There were good relations between the RTV7 (V7) and the observed precipitation in the Ganjiang River basin and it was clear that the RTV7 and V7 slightly underestimated precipitation. The RTV7 showed better performance with high CC (0.85) and slight underestimation by $0.56 \%$. The V7 showed much better performance with higher CC (0.86) and lower RMSE with the value of $4.23 \mathrm{~mm}$.

3.2. Extreme Precipitation Analysis in the Ganjiang River Basin. The precipitation of the $95 \%$ threshold ( $95 \% \mathrm{pr}$ ), the highest 1 day (H1Dpr), and highest 7 day (H7Dpr) were analyzed to reveal the changing features of extreme precipitation in the Ganjiang River basin. The spatial pattern of the $95 \% \mathrm{pr}$ was similar to that of annual mean precipitation (Figure 2(a) versus Figure 4(a)), and the same thing could happen to the RTV7 (Figure 2(b) versus Figure 4(b)) and V7 (Figure 2(c) versus Figure 4(c)). H1Dpr and H7Dpr as a whole increased from south to north. The annual mean extreme precipitation was $21.8 \mathrm{~mm}$ for the $95 \%$ threshold over the Ganjiang River basin based on the observed precipitation. However, it was $25.6 \mathrm{~mm}$ and $25.7 \mathrm{~mm}$ for the RTV7 and V7, respectively. The observed extreme precipitation for the frequency of $95 \%$ was $15.9 \mathrm{~d} / \mathrm{a}$, and the extreme precipitation intensity was $31 \mathrm{~mm} / \mathrm{d}$, while the estimated extreme precipitation by RTV7 and V7 for the frequency of $95 \%$ was $13 \mathrm{~d} / \mathrm{a}$ and $12.8 \mathrm{~d} / \mathrm{a}$, and the intensity was $36.7 \mathrm{~mm} / \mathrm{d}$ and $36.7 \mathrm{~mm} / \mathrm{d}$, respectively.

The areas with less extreme higher precipitation are mainly concentrated in the southern part of Ganjiang River basin, and lower precipitation was found in the middle reaches (Figures $4(\mathrm{a})-4(\mathrm{c})$ ). It can also be seen that both of V7 and RTV7 overestimated the extreme precipitation for the 95\% threshold; especially the RTV7 overestimated it more clearly. The extreme precipitation variabilities in the Ganjiang varied greatly. The spatial distribution of the extreme precipitation for H1Dpr in the Ganjiang River basin was similar to that of $95 \%$ threshold and higher values can be found in the north area (Figures 4(d)-4(f)). However the 


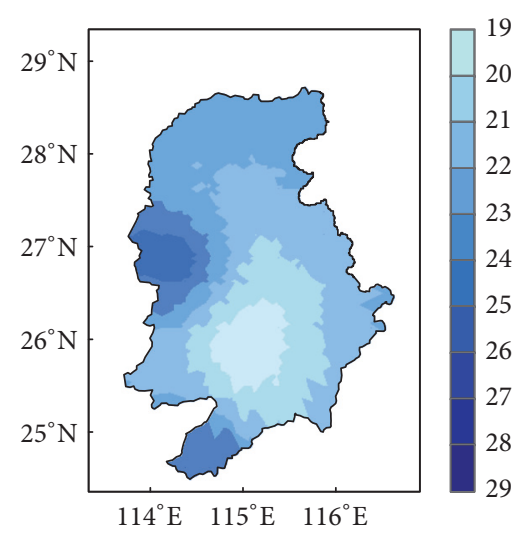

(a) Obs_95\%

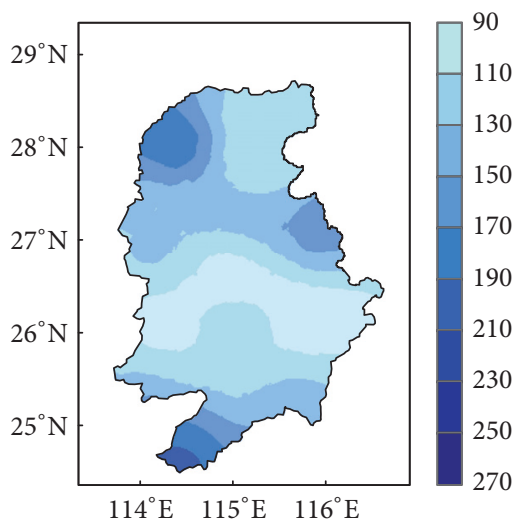

(d) Obs_H1D

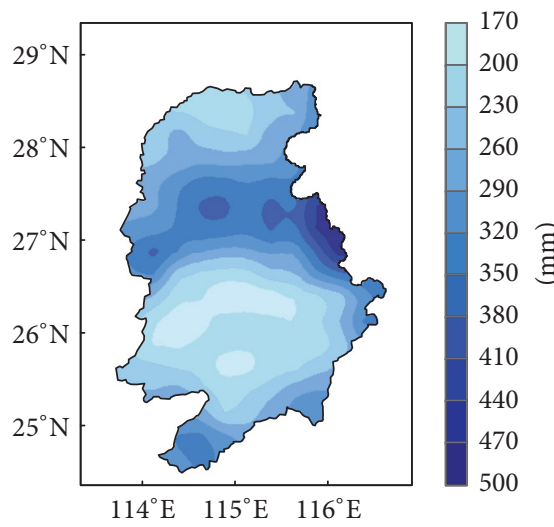

(g) Obs_H7D
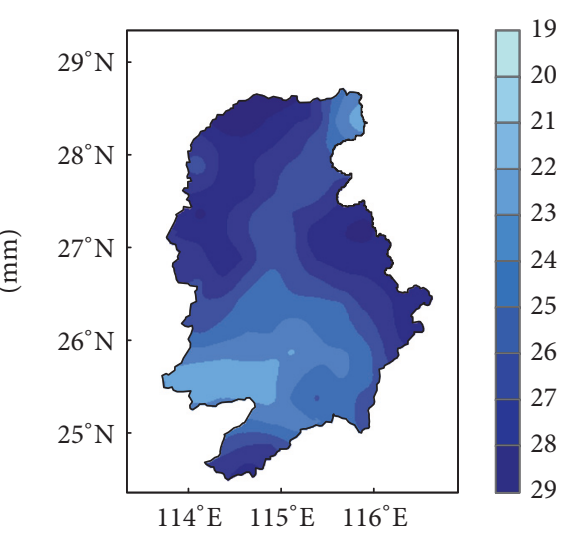

(b) RTV7_95\%

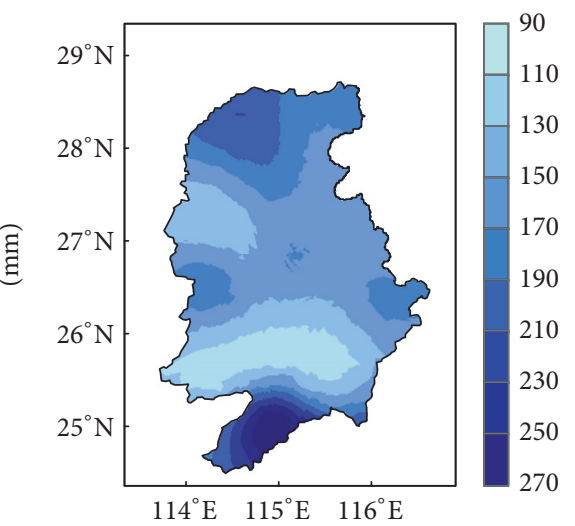

(e) RTV7_H1D

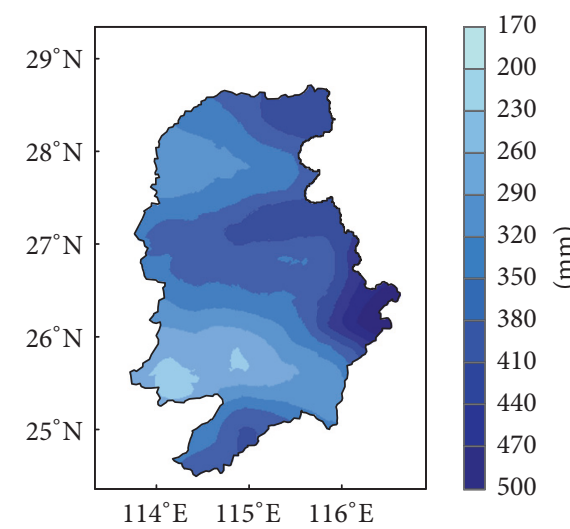

(h) RTV7_H7D

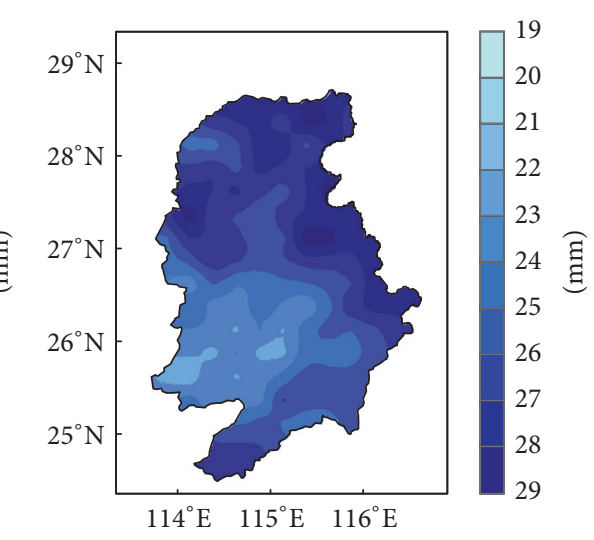

(c) V7_95\%

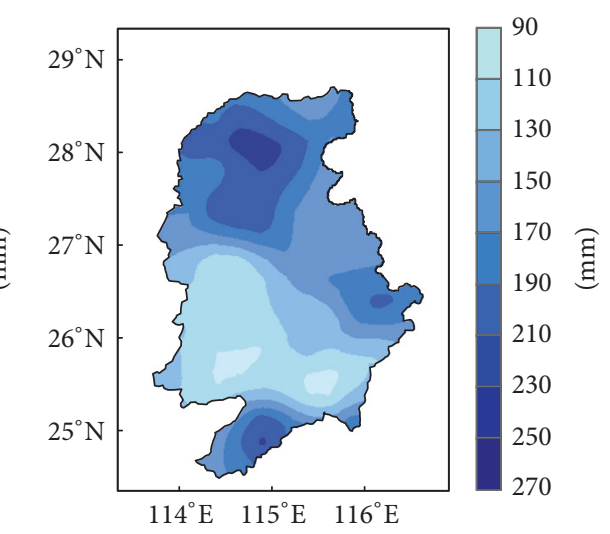

(f) V7_H1D

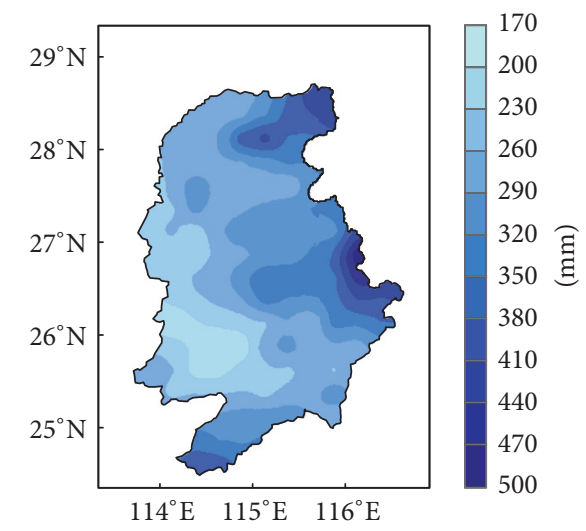

(i) V7 H7D

FIGURE 4: Spatial distribution of the extreme value of precipitation in the Ganjiang River basin from TMPA from 2003 to 2010.

southern region of the simulation is closer to the observation. As for the H7Dpr, the extreme precipitation in the middle and upper reaches of Ganjiang River basin increased markedly compared with $95 \%$ and H1Dpr, and the southern region is still showing less precipitation. The simulation results of H7Dpr by RTV7 and V7 were better than those of $95 \%$ and H1Dpr obviously, especially V7, whose simulation was more close to that of observation (Figures $4(\mathrm{~g})-4(\mathrm{i})$ ).

3.3. Extreme Streamflow Analysis in the Ganjiang River Basin. The VIC hydrological model was used in this paper and the corresponding parameters and calibration results were showed in Table 1 , and the NSCE, CC, and RB were 0.829 , 0.929 , and -0.152 . It can be seen that the pattern of the simulated streamflow was similar to that of observed streamflow during the calibration period (Figure 5). Accordingly, the simulated streamflow was also similar to that of observed streamflow during the verification period.

The simulated streamflow by VIC hydrological model driven by observed precipitation and RTV7/V7 products of the Ganjiang River basin was as shown in Figure 6. We can find that the simulated streamflow driven by RTV7/V7 
TABLE 1: VIC model calibrated parameters and calibrated values in Ganjiang River basin.

\begin{tabular}{lccc}
\hline Number & Parameters & Definition & Calibrated value \\
\hline 1 & $B$ & Variable infiltration curve parameter (binfilt) & 0.236 \\
2 & $W s$ & Fraction of maximum soil moisture where nonlinear baseflow occurs & 0.533 \\
3 & $D s$ & Fraction of $D$ smax where nonlinear baseflow begins & 0.481 \\
4 & $D s \max$ & Maximum velocity of baseflow & 13.748 \\
5 & $d 0$ & & 0.300 \\
6 & $d 1$ & Thickness of each soil moisture layer & 2.430 \\
7 & $d 2$ & & 0.533 \\
\hline
\end{tabular}

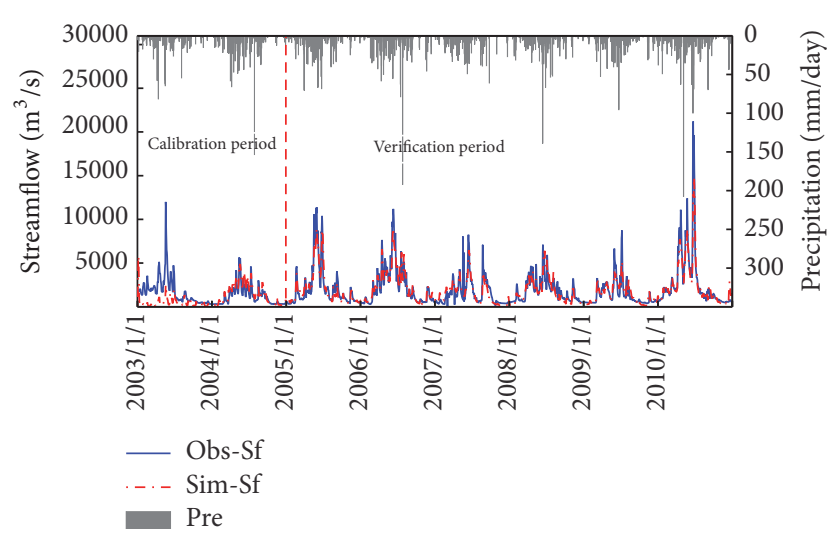

FigURE 5: Daily precipitation, observed streamflow, and simulated streamflow by VIC model in the Ganjiang River basin from 2003 to 2010.

precipitation agreed well with that of observed precipitation, and the TMPA products had good results in capturing the pattern of streamflow in the Ganjiang River basin. The NSCE and CC value were 0.70 and 0.86 for the RTV7 product in the Ganjiang River basin, respectively. And the streamflow driven by V7 products was better than that of RTV7 with higher NSCE value (0.79) and higher CC value (0.89). So the evaluation of the $\mathrm{V} 7$ product applying in the hydrological simulation was better than that of RTV7.

Figure 7 showed the annual mean streamflow and the extreme streamflow driven by the observed precipitation and RTV7/V7 products in the Ganjiang River basin from 2003 to 2010 . The streamflow of the $95 \%$ threshold ( $95 \%$ sf), the highest 1-day streamflow (H1Dsf), highest 3-day streamflow (H3Dsf), highest 5-day streamflow (H5Dsf), and highest 7day streamflow (H7Dsf) were analyzed in this paper. The results showed that the RTV7/V7 could capture the main patterns of the extreme streamflow in the Ganjiang River basin by using VIC hydrological model. There were good relationships between the observed and simulated extreme streamflow in the Ganjiang River basin, although the RTV7 overestimated the extreme streamflow (Figure 7). The observed maximum and minimum annual streamflow was $2893.8 \mathrm{~m}^{3} / \mathrm{s}$ and $1410.4 \mathrm{~m}^{3} / \mathrm{s}$, respectively, while the simulated maximum streamflow driven by gauged precipitation, RTV7, and V7 products were $2599.4,2626.2,2719.0 \mathrm{~m}^{3} / \mathrm{s}$, respectively.
And the simulated minimum streamflow by gauged precipitation, RTV7 and V7 products were 1335.1, 1327.2, and $1372.8 \mathrm{~m}^{3} / \mathrm{s}$, respectively.

\section{Discussion}

Many researchers had found that TRMM RTV7 (V7) products had good abilities in analyzing the changes of precipitation in the world [2, 28]. For example, Almazroui [29] revealed the temporal and spatial distribution characteristics of precipitation in Saudi Arabia by using the TRMM 3B42 data. Cai et al. [30] applied the 3B42 V7 data with mid-high latitudes, they found that $3 \mathrm{~b} 42 \mathrm{~V} 7$ had good accuracy, and it was consistent with the measured characteristics of rainfall. These results are consistent with the results of our study.

Although the application of TRMM products for hydrological was limited, a few researches had been conducted. For example, Yong et al. [31] and Behrangi et al. [16] evaluated the accuracy and hydrological simulation utility of the TRMM 3B42 data at the Laohahe basin and the Illinois River basin, respectively. Both studies have been found that the deviation of 3B42RT precipitation data is large, but 3B42V6 is relatively small. Compared with 3B42RT, the accuracy 3B42V6 simulated the runoff higher. Huang et al. $[9,10]$ found that the TRMM 3B42 V7 and RTV7 have high accuracy in estimating rainfall and the RTV7 (V7) products can better reproduce the runoff process at a certain scale. This is consistent with our results, indicating that the accuracy of the RTV7 (V7) satellite precipitation data has been improved and are more suitable for streamflow simulation.

Although there has been a noticeable improvement in the evaluation of satellite-based precipitation products, many researches indicated that the satellite-based precipitation has larger measurement uncertainties over complex terrains [32]. Heidinger et al. (2012) evaluated the TMPA precipitation products over the Andean Plateau and they reported that rainfall estimates from the TRMM satellite exhibit inaccuracies over topographically complex regions. Zhang et al. [32] found the performance of TMPA precipitation evaluation showed a downward trend with increasing altitude in the Yangtze River basin. Zhu et al. [27] found that the error between the TRMM data and the measured data decreases as the elevation increases in Hengduan Mountains region. In our research, there are many mountains in the Ganjiang River basin which might affect the precipitation estimation, 


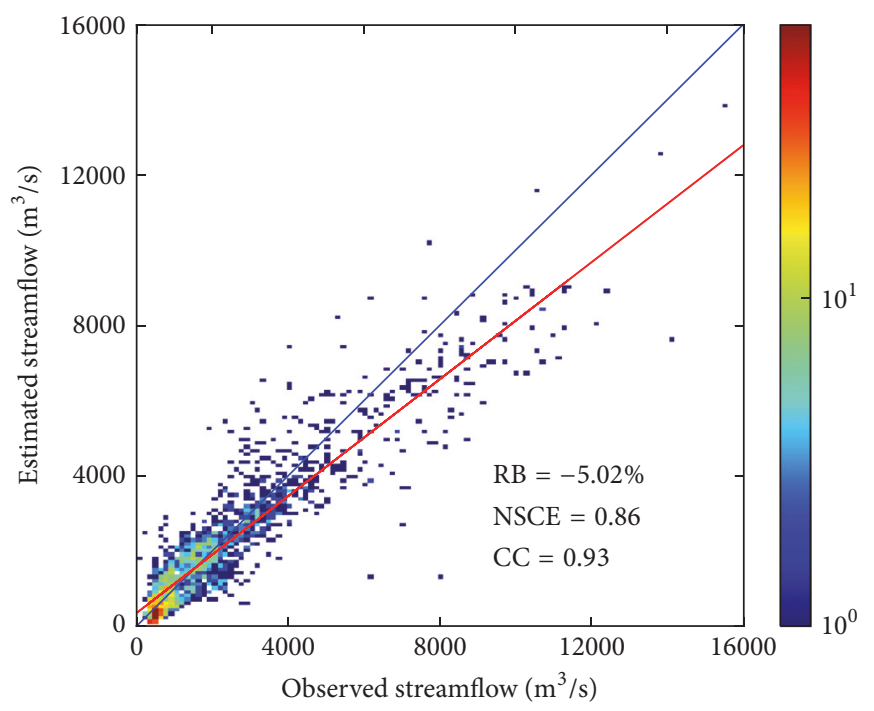

(a) VIC-Gauge

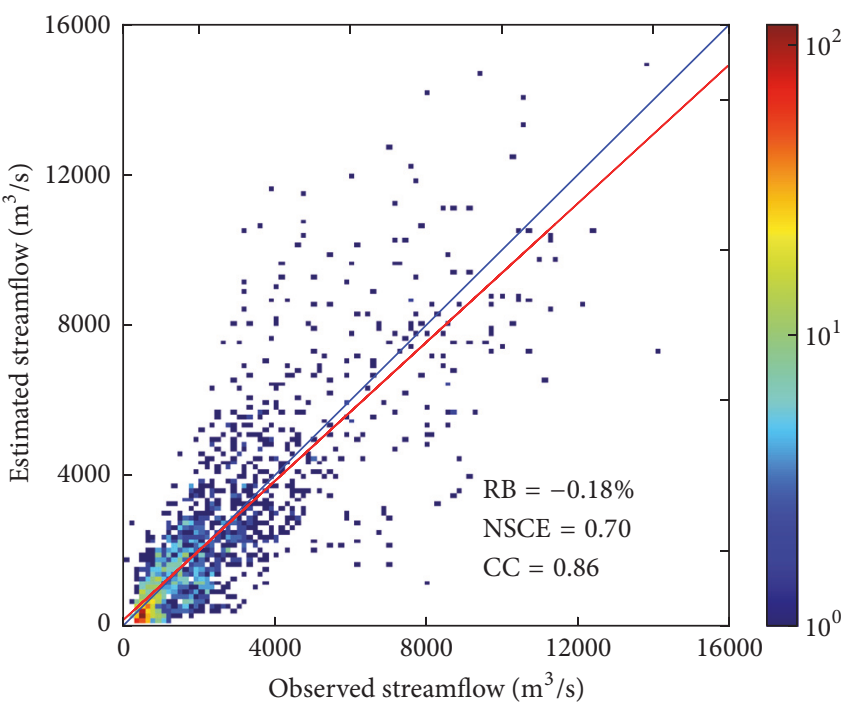

(b) VIC-RTV7

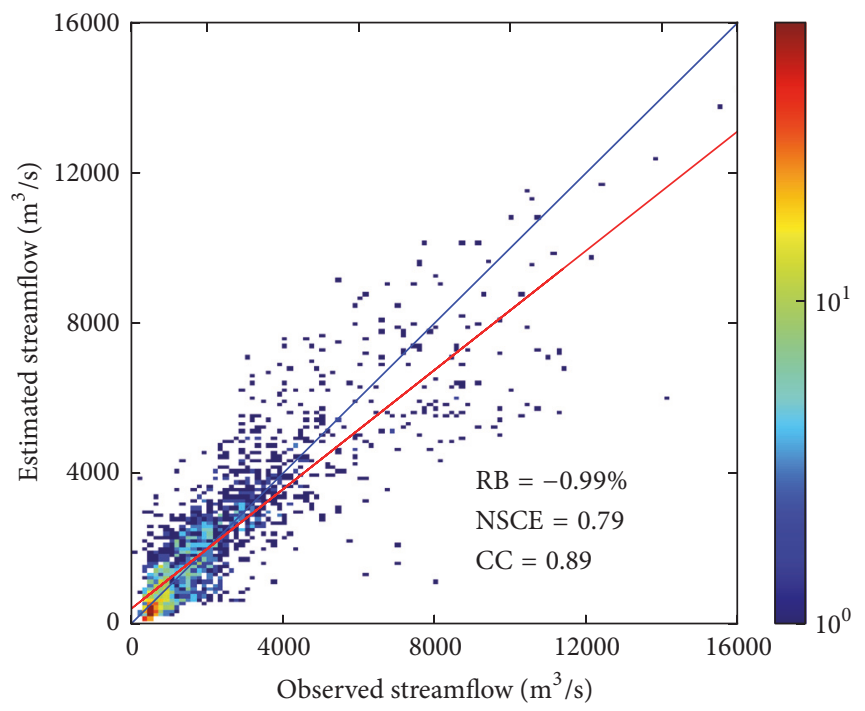

(c) VIC-V7

FIGURE 6: Scatter plots of the observed and simulated streamflow by using VIC hydrological model in the Ganjiang River basin.

especially in the western and southern river basin. Since the actual precipitation at high altitude is higher than that at low altitude, different elevations have effects on satellite rainfall accuracy. Therefore, although the performance of 3B42 RTV7 (V7) has been improved, more work should be done to improve it.

Few works has been conducted on the extreme precipitation and streamflow by using the TRMM RTV7 and V7 products; however, it still has great development space in the future [17, 33] (Dai et al., 2005). For example, Yong et al. [34] compared the real-time 3B42RT estimates (RTV6 and RTV7) and post-real-time 3B42 estimates (V6 and V7) for water resources and hydrologic extremes over high and low latitudes basins; all statistics indicated that real-time RTV7 has almost reached the accuracy level of the post-real-time reached products, and all products underestimated the precipitation amounts for strong events $(>128 \mathrm{~mm} /$ day $)$ in the low-latitude Mishui basin. Jamandre and Narisma [35] conducted a detailed study on the availability of TRMM 3B42 satellite data in the Philippines, and they found that TRMM satellite data can well capture the extreme precipitation events, and the accuracy of the northern part of the Philippines was higher than that of the southern part of the country. Dong et al. [36] also found there was an ideal linear relationship between watershed precipitation and flow in the Huaihe River basin and they thought that there was a good relationship between the extreme precipitation and extreme streamflow. Thus, it is concluded that the accuracy of satellite precipitation products depends on the geographical location and the measured precipitation level. 


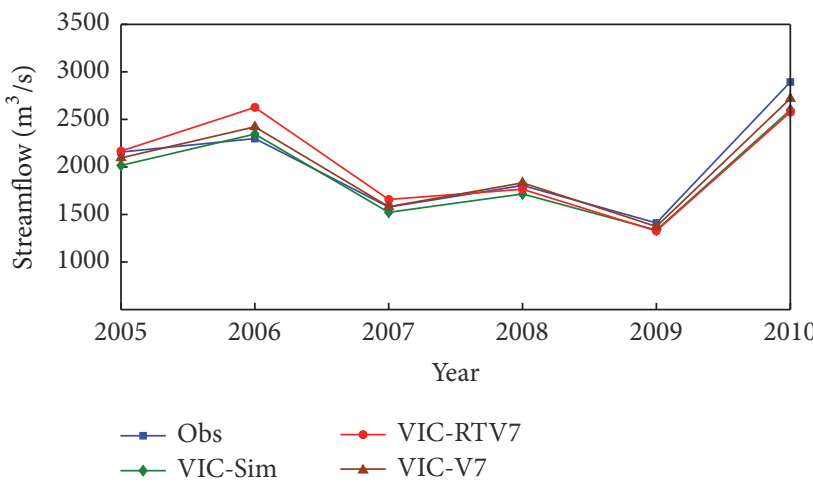

(a) Annual mean streamflow

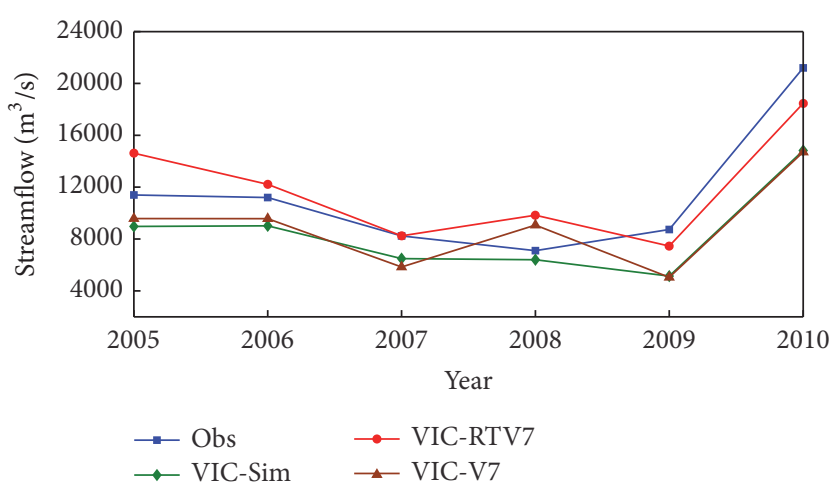

(c) H1D

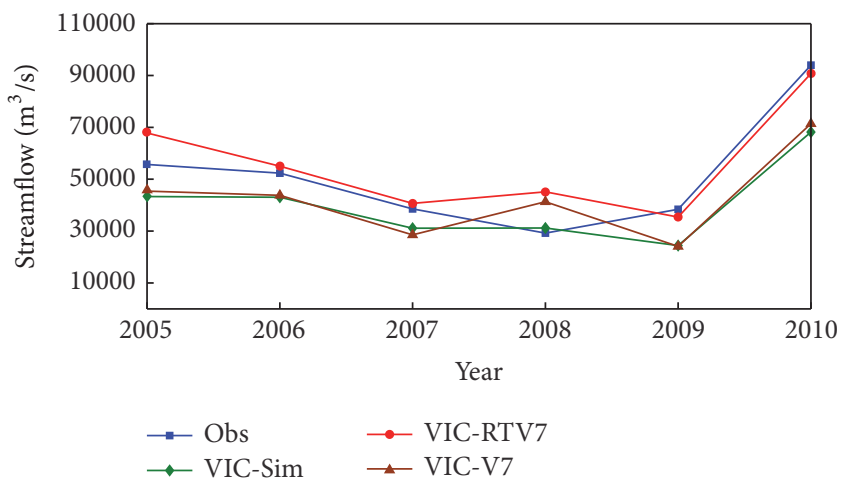

(e) $\mathrm{H} 5 \mathrm{D}$

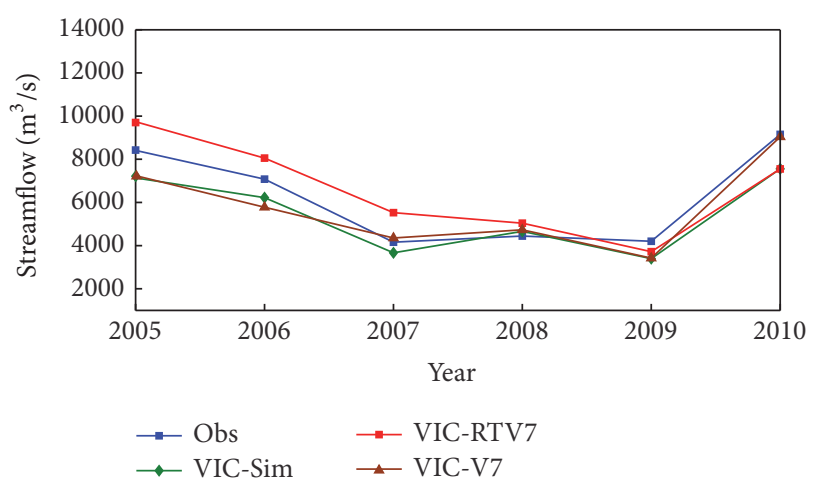

(b) $95 \%$

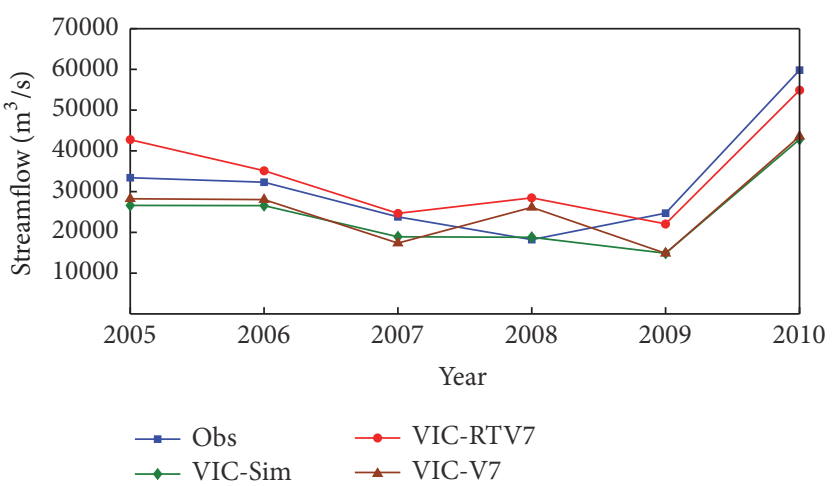

(d) H3D

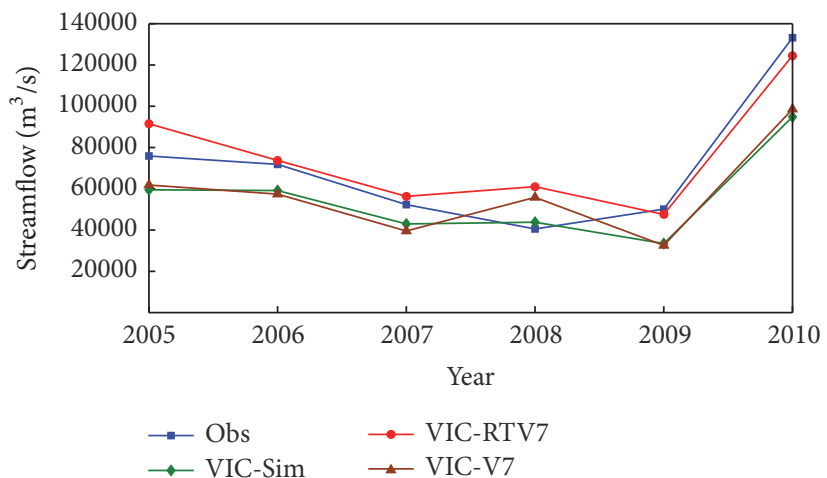

(f) H7D

FIGURE 7: The annual mean streamflow, the extreme value of streamflow of RTV7 and V7, and observed value and simulated value by VIC model in the Ganjiang River Basin from 2003 to 2010.

\section{Conclusions}

Based on the observed precipitation and TRMM RTV7 (V7) precipitation products, the changes of extreme precipitation and extreme streamflow in the Ganjiang River basin were analyzed by using the VIC hydrological model. The main results were as follows:

(1) The RTV7 and V7 TMPA products have similar pattern to that of observed precipitation in the Ganjiang River basin, and the $\mathrm{V} 7$ product had been significantly improved compared to that of RTV7 for the whole basin. The RTV7 showed better performance with high CC (0.85) and slight underestimation by $0.56 \%$.
The V7 showed much better performance with higher CC (0.86) and lower RMSE with the value of $4.23 \mathrm{~mm}$.

(2) The spatial pattern of the extreme precipitation was similar to that of annual mean precipitation and the extreme precipitation increased from south to north in the Ganjiang River basin. The areas with less extreme higher precipitation are mainly concentrated in the southern part of Ganjiang River basin, and lower precipitation was found in the middle reaches. It can also be seen that both of V7 and RTV7 overestimated the extreme precipitation for the 95\% threshold; especially the RTV7 overestimated it more clearly. 
(3) The simulated streamflow driven by RTV7/V7 precipitation agreed well with that of observed streamflow, and the NSCE and CC values were 0.70 (0.79) and $0.86(0.89)$ for the RTV7 (V7) products in the Ganjiang River basin, respectively. The RTV7/V7 could capture the main patterns of the extreme streamflow in the Ganjiang River basin by using VIC hydrological model. There were good relationships between the observed and simulated extreme streamflow in the Ganjiang River basin, although the RTV7 overestimated the extreme streamflow. This research might be helpful to promote the extreme precipitation and streamflow by using the satellite precipitation products, although there are still a lot of problems and difficulties.

\section{Conflicts of Interest}

The authors declare that they have no conflicts of interest.

\section{Acknowledgments}

This paper is financially supported by National Natural Science Foundation of China (Grant nos. 51190090 and 41171020), Distinguished Young Scholars Fund of Nanjing Forestry University, Open Research Fund Program of State Key Laboratory of Water Resources and Hydropower Engineering Science (Grant no. 2011B079), Key Laboratory of Watershed Geographic Sciences, Chinese Academy of Sciences (Grant no. WSGS2015005), the State Key Laboratory of Satellite Ocean Environment Dynamics, Second Institute of State Oceanic Administration, Six Talent Peaks Project in Jiangsu Province (Grant no. 2015-JY-017), and the Priority Academic Program Development of Jiangsu Higher Education Institutions (PAPD). The authors would like to thank the National Climate Centre in Beijing for providing valuable climate datasets.

\section{References}

[1] E. Habib, A. Henschke, and R. F. Adler, "Evaluation of TMPA satellite-based research and real-time rainfall estimates during six tropical-related heavy rainfall events over Louisiana, USA," Atmospheric Research, vol. 94, no. 3, pp. 373-388, 2009.

[2] W. S. Han, S. J. Burian, and J. M. Shepherd, "Assessment of satellite-based rainfall estimates in urban areas in different geographic and climatic regions," Natural Hazards, vol. 56, no. 3, pp. 733-747, 2011.

[3] G. Montero-Martinez, V. Zarraluqui-Such, and F. GarciaGarcia, "Evaluation of 2B31 TRMM-product rain estimates for single precipitation events over a region with complex topographic features," Journal of Geophysical Research-Atmospheres, vol. 117, no. 2, Article ID D02101, 2012.

[4] Z.-Y. Yin, X. Zhang, X. Liu, M. Colella, and X. Chen, "An assessment of the biases of satellite rainfall estimates over the Tibetan plateau and correction methods based on topographic analysis," Journal of Hydrometeorology, vol. 9, no. 3, pp. 301-326, 2008.
[5] Z. Liu, "Comparison of versions 6 and 7 3-hourly TRMM multi-satellite precipitation analysis (TMPA) research products," Atmospheric Research, vol. 163, pp. 91-101, 2015.

[6] K. Tong, F. Su, D. Yang, L. Zhang, and Z. Hao, "Evaluation of satellite precipitation retrievals and their potential utilities in hydrologic modeling over the tibetan plateau," Journal of Hydrology Part A, vol. 519, pp. 423-437, 2014.

[7] H. Zhao, S. Yang, Z. Wang, X. Zhou, Y. Luo, and L. Wu, "Evaluating the suitability of TRMM satellite rainfall data for hydrological simulation using a distributed hydrological model in the Weihe River catchment in China," Journal of Geographical Sciences, vol. 25, no. 2, pp. 177-195, 2015.

[8] J. Xiong, D. Mao, and N. Yan, "Evaluation of TRMM satellite precipitation product in hydrologic simulations of hai basin," River Basin Research and Planning Approach, pp. 180-186.

[9] Y. H. Huang, Z. X. Zhang, M. Z. Fei, and Q. Jin, "Hydrological evaluation of the TMPA multisatellite precipitation estimates over the Gangjiang basin," Resources and Environment in the Yangtze Basin, vol. 10, pp. 1618-1625, 2016.

[10] Y. Huang, Z. Zhang, and Q. Jin, "Evaluation of TRMM satellite rainfall in driving variable infiltration capacity (VIC) model in Ganjiang basin," in Proceedings of the 5th International Conference on Civil Engineering and Transportation, Y. H. Kim, Ed., pp. 1048-1051, AER-Advances in Engineering Research, Guangzhou, China, 2015.

[11] A. J. Bai, J. G. Fang, and K. X. Zhang, "Summer rainfall in Shaanxi and its neighborhood regions observed by TRMM satellite," Ournal of Catastrophology, vol. 2, pp. 41-45, 2008a.

[12] A. J. Bai, C. H. Liu, and X. D. Liu, "Diurnal variation of summer rainfall over the Tibetan Plateau and its neighboring regions revealed by TRMM multi-satellite precipitation analysis," Chinese Journal of Geophysics, vol. 3, pp. 704-714, $2008 \mathrm{~b}$.

[13] F. Yuan, J. Zhao, L. Ren, S. Jiang, Y. Zhou, and Z. Yin, "Streamflow simulation in the upper Ganjiang river basin using the TRMM multi-satellite precipitation data," Journal of Tianjin University (Science and Technology), vol. 46, no. 7, pp. 611-616, 2013.

[14] S. Chen, Y. Hong, Q. Cao et al., "Similarity and difference of the two successive V6 and V7 TRMM multisatellite precipitation analysis performance over China," Journal of Geophysical Research Atmospheres, vol. 118, no. 23, pp. 13060-13074, 2013.

[15] X. Q. Yang and W. J. Geng, "Accuracy evaluation of trmm-based multi-satellite precipitation in huai river basin," Water Resources and Power, vol. 07, pp. 1-5, 2016.

[16] A. Behrangi, B. Khakbaz, T. C. Jaw, A. AghaKouchak, K. Hsu, and S. Sorooshian, "Hydrologic evaluation of satellite precipitation products over a mid-size basin," Journal of Hydrology, vol. 397, no. 3-4, pp. 225-237, 2011.

[17] X. Xue, Y. Hong, A. S. Limaye et al., "Statistical and hydrological evaluation of TRMM-based Multi-satellite Precipitation Analysis over the Wangchu Basin of Bhutan: are the latest satellite precipitation products $3 \mathrm{~B} 42 \mathrm{~V} 7$ ready for use in ungauged basins?" Journal of Hydrology, vol. 499, pp. 91-99, 2013.

[18] S. Jiang, L. Ren, B. Yong, F. Yuan, L. Gong, and X. Yang, "Hydrological evaluation of the TRMM multi-satellite precipitation estimates over the Mishui basin," Advances in Water Science, vol. 25, no. 5, pp. 641-649, 2014.

[19] F. Su, Y. Hong, and D. P. Lettenmaier, "Evaluation of TRMM multisatellite precipitation analysis (TMPA) and its utility in hydrologic prediction in the la plata basin," Journal of Hydrometeorology, vol. 9, no. 4, pp. 622-640, 2008a. 
[20] M. Pan, E. F. Wood, R. Wojcik, and M. F. McCabe, "Estimation of regional terrestrial water cycle using multi-sensor remote sensing observations and data assimilation," Remote Sensing of Environment, vol. 112, no. 4, pp. 1282-1294, 2008.

[21] G. Tang, Z. Li, X. Xue, Q. Hu, B. Yong, and Y. Hong, "A study of substitutability of TRMM remote sensing precipitation for gauge-based observation in Ganjiang river basin," Advances in Water Science, vol. 26, no. 3, pp. 340-346, 2015.

[22] S. Chen, J. Hu, Z. Zhang et al., "Hydrologic Evaluation of the TRMM Multisatellite Precipitation Analysis over Ganjiang Basin in Humid Southeastern China," IEEE Journal of Selected Topics in Applied Earth Observations and Remote Sensing, vol. 8, no. 9, pp. 4568-4580, 2015.

[23] X. H. Li, Q. Zhang, and C.-Y. Xu, "Suitability of the TRMM satellite rainfalls in driving a distributed hydrological model for water balance computations in xinjiang catchment, poyang lake basin," Journal of Hydrology, vol. 426, pp. 28-38, 2012.

[24] X. Li, Q. Zhang, and X. Ye, "Dry/wet conditions monitoring based on TRMM rainfall data and its reliability validation over Poyang Lake Basin, China," Water, vol. 5, no. 4, pp. 1848-1864, 2013b.

[25] F. G. Su, Y. Hong, and D. P. Lettenmaier, "Evaluation of TRMM multisatellite precipitation analysis (TMPA) and its utility in hydrologic prediction in the la plata basin," Journal of Hydrometeorology, vol. 9, no. 4, pp. 622-640, 2008 b.

[26] L. K. Yan, "Application of correlation coefficient and biased correlation coefficient in related analysis," Journal of Yunnan University of Finance and Economics, vol. 03, pp. 78-80, 2003.

[27] G. F. Zhu, T. Pu, T. Zhang et al., "The accuracy of TRMM precipitation data in hengduan mountainous region, China," Scientia Geographica Sinica, pp. 1125-1131, 2013.

[28] E. Tarnavsky, M. Mulligan, and G. Husak, "Spatial disaggregation and intensity correction of TRMM-based rainfall time series for hydrological applications in dryland catchments," Hydrological Sciences Journal-Journal Des Sciences Hydrologiques, vol. 57, no. 2, pp. 248-264, 2012.

[29] M. Almazroui, "Calibration of TRMM rainfall climatology over Saudi Arabia during 1998-2009," Atmospheric Research, vol. 99, no. 3-4, pp. 400-414, 2011.

[30] Y.-C. Cai, C.-J. Jin, A.-Z. Wang et al., "Accuracy evaluation of the TRMM satellite-based precipitation data over the mid-high latitudes," Chinese Journal of Applied Ecology, vol. 25, no. 11, pp. 3296-3306, 2014

[31] B. Yong, L.-L. Ren, Y. Hong et al., "Hydrologic evaluation of Multisatellite Precipitation Analysis standard precipitation products in basins beyond its inclined latitude band: a case study in Laohahe basin, China," Water Resources Research, vol. 46, no. 7, Article ID W07542, 2010.

[32] Z. Zhang, Q. Jin, X. Chen et al., "Evaluation of TRMM Multisatellite Precipitation Analysis in the Yangtze River Basin with a Typical Monsoon Climate," Advances in Meteorology, vol. 2016, pp. 1-13, 2016.

[33] T. Zhou, R. Yu, H. Chen, A. Dai, and Y. Pan, "Summer precipitation frequency, intensity, and diurnal cycle over China: a comparison of satellite data with rain gauge observations," Journal of Climate, vol. 21, no. 16, pp. 3997-4010, 2008.

[34] B. Yong, B. Chen, J. J. Gourley et al., "Intercomparison of the Version-6 and Version-7 TMPA precipitation products over high and low latitudes basins with independent gauge networks: is the newer version better in both real-time and post-real-time analysis for water resources and hydrologic extremes?" Journal of Hydrology, vol. 508, pp. 77-87, 2014.
[35] C. A. Jamandre and G. T. Narisma, "Spatio-temporal validation of satellite-based rainfall estimates in the Philippines," Atmospheric Research, vol. 122, pp. 599-608, 2013.

[36] Q. Dong, X. Chen, T. X. Chen, and X. W. Cheng, "Relationship between extremes of precipitation and discharge in the Huaihe river basin," Journal of Nanjing University (Natural Sciences), vol. 6, pp. 790-801, 2009. 

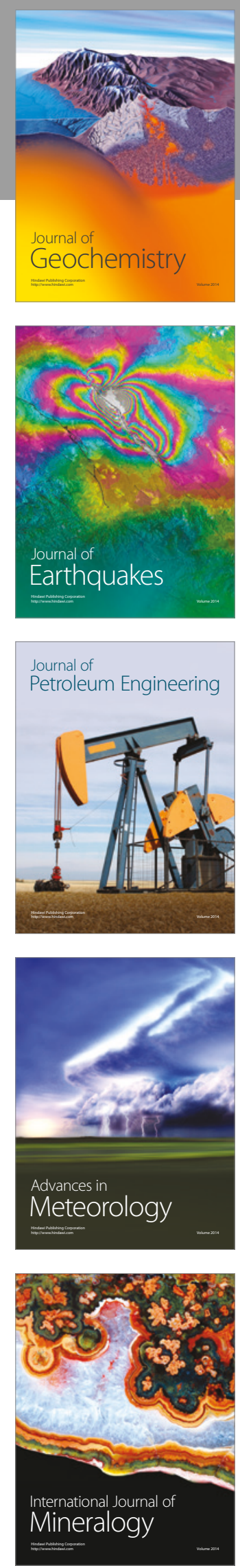
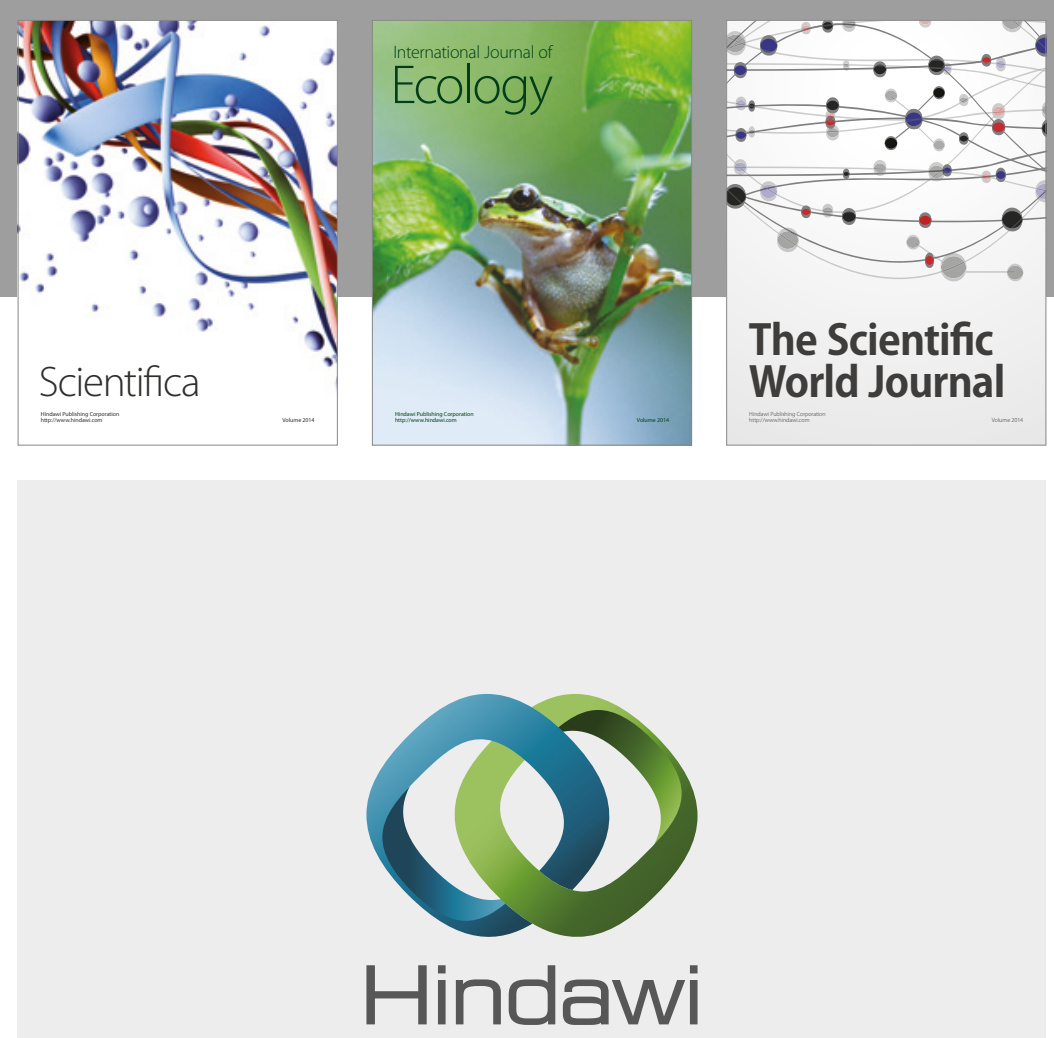

Submit your manuscripts at

https://www.hindawi.com
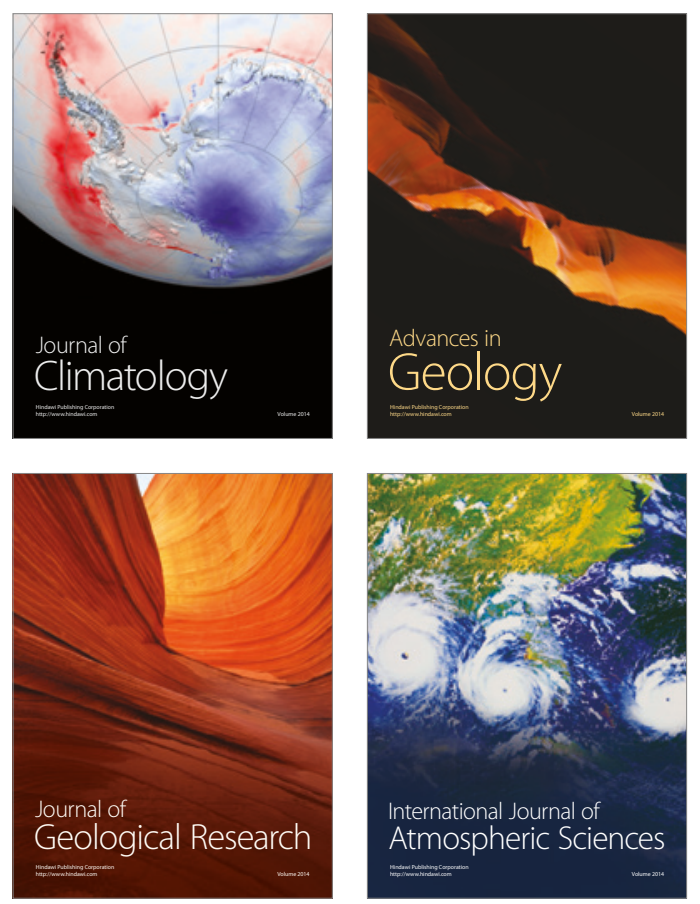

The Scientific

World Journal
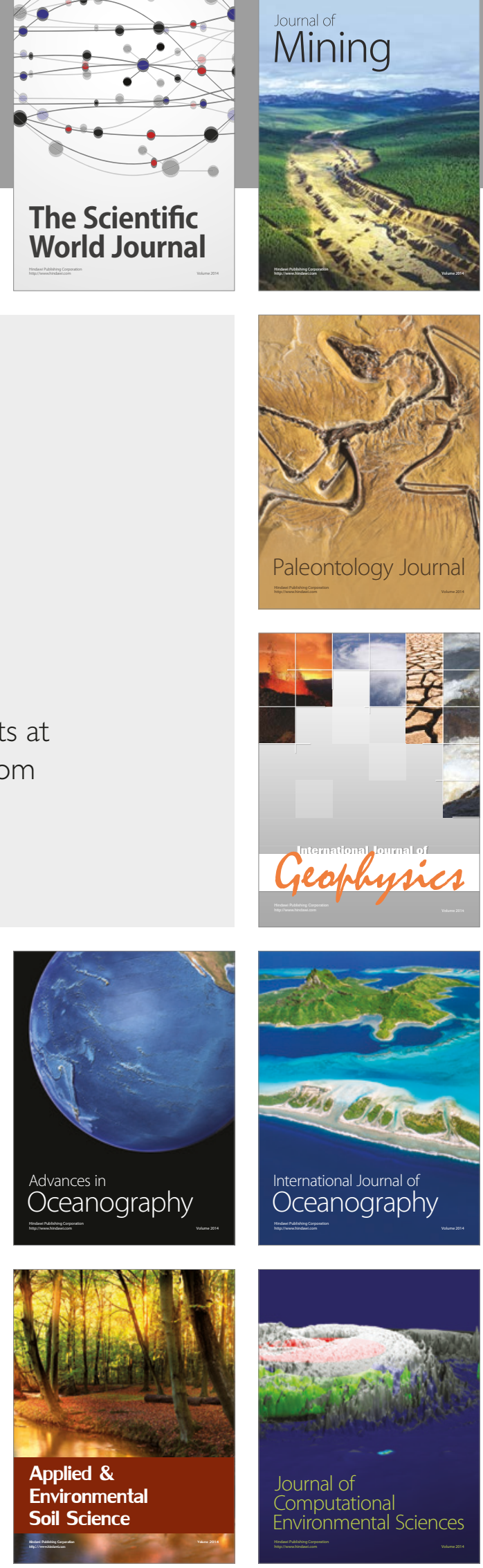